\title{
IV. Ueber ein neues Princip zur Erzeugung constanter Temperaturen und seine specielle Anwendung auf die Sterilisation von Blut- serum.
}

\section{Von}

Dr. Carl Roth,

vereideten Chemiker in Berlin.

Inhaber eines Laboratoriuns für Herstelluug ron Nährböden.

Eine der Hauptschwierigkeiten, welche sich dem Sterilisireı vou Blutserum entgegenstellell, bestelıt in der mit geradezu pedantisclier Sorgfalt zu regulirendeu Würmezufulır zu dem Sterilisationsmaterial, wenn auders malı iu keius der so eng limitirten Temperatur-Extreme, welche für den Ausfall des Präparates so leiclıt verhänguissvoll werden, verfalleı will. Wird nämliclı die Maximalgrenze der Temperatur vou $59^{\circ} \mathrm{C}$. niclit möglichsst vollkommeı während 5-6 Tagen 4-5 Stunden lang iınegehalteı, so läuft man Gefahr, dass niclit alle Keime getödtet werden, und die unter alleı Umständen anzustrebende absolute Sterilität wird dadurclı illusorisclı. Wird andererseits diese Maximaltemperatur auch nur auf Stunden um 5--7 Decigrade überschrittelı, so tritt lıäufig vorzeitige Coagulation und damit Uudurchsichtigkeit des Serums eill. Obgleich die thermische Grenze der Geriunungsfähigkeit des Serums selbst für Thiere einer und derselbeı Gattung individuell ist, darf maı doch in deı selteısteı Fälleı bei einer Temperatur von 60 Centigraden ungestraft aucl nur wenige Stundeı steheı bleibeıl. Alles in Allem genommen, erheischt dennaclı die Construction der bisher zur Innelialtung der oben angefülırten Temperaturgrenzen angewandten Thermo - und Gasdruckregulatoreı die grösste Sorgfalt und die Bedieıung derselben eine trotz aller angewandten mechanischen Finessen unausgesetzte Aufmerksamkeit. Der ganze mechanische Thermoregulirungsapparat ist - abgesehen vou dem Uebelstand, dass er nur eine locale Bedeutung für die mit Gas ausgestatteten Laboratorien hat und deshalb für einen grossen Theil der mit bakterioskopischıı Arbeiten beschäftigteı Landärzte gar nicht in Frage kommen kanlı - viel zu compendiös.

Ich habe aus dieseı Gründeıl das mechanische Regulirungspriıcip verlasseı und einen Apparat construirt, der neben der Annehmlichkeit einer bequemen Handlabung den Vortheil bietet automatisch $z u$ fungireı, allerorts anwendbar zu seiı und grössere thermische Sicherheiteı zu gewälıreı als dies bei Apparateı jener Klasse der Fall ist.

Ich bediene mich zur Erzeugung der erforderlichen coustanteı Wärme der ungespanıteı Däunfe eines Körpers vou constanteu Siedepunkt, des Cliloroforns, und eines anderen, des Benzins, nuit dem ich ihn in abwärts steigender Linie, je ıach dem grössereı oder geringeren Zusatz aul letzterem, variabel mache, sowie des Princips des Rïckflusskühlers. Reines Clıloroform' ${ }^{\prime}$ ) siedet bei $61^{\circ} \mathrm{C}$., der Pe-

1) Ieh fügè $100 \mathrm{ccu}$ Chloroforn 5-6 Tropfen Aethylalkohol liin\%u, weil hierdurcl das Präparat haltbar und jede Abspaltung von Salssäure? vermieden wird. 


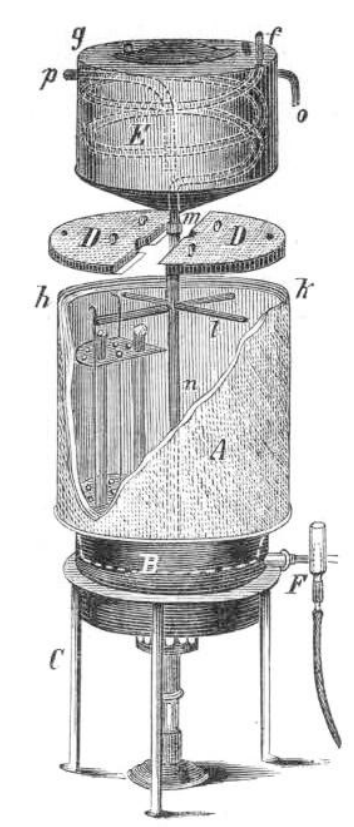

troleumäther der Ph. - Germ. zwischen 55 und $75^{\circ} \mathrm{C}$. Vermischt man Chloroform mit 10 Volumprocenten des letzteren, so weist die Mischung, falls die Dämpfe vollkommen condensirt nach dem Ausgangspunkt quantitativ zurückgeführt werden, einen constanten Siedepunkt von $59^{\circ} \mathrm{C}$. auf. Der erforderliche Apparat, welcher durch die beigegebene Skizze veranschaulicht wird, setzt sich aus drei Theilen zusammen.

Das Wasserbad B, welches nebenbei bemerkt, wegfallen kann, umschliesst das zum Erwärmen der Mischung dienende Siedebassin, das sich in dem Hohlmantel Akh fortsetzt, und dessen äussere und innere Wand circa $2 \mathrm{~cm}$ von einander entfernt sind. Vom oberen Bodentheil des Siedebassins geht das Messingrohr $\mathrm{n}$ aus, welches bei $\mathrm{m}$ durch Konusverschluss mit der Kühlschlange $\mathrm{E}$ hermetisch verbunden werden kann. Das gasometerartig aufgesetzte Reservoir $g$ dient zur Aufnahme des Kühlwassers, welches bei $p$ ein- und bei 0 austritt und das gleichzeitig zur Speisung des Wasserbades mit constantem Niveau benutzt werden kann. Von dem vertikalen Hauptrohr $n$ zweigen sich in horizontaler Richtung vier sich unter rechten Winkeln schneidende Messingröhren ab, die mit dem Mantel Akh und dem mittleren Hauptrohr $\mathrm{n}$ communiciren. Der Apparat ist durch die beiden mit Asbest isolirten Halbbohldeckel DD verschliessbar. Die innere Temperatur des Sterilisationsraumes wird durch ein in den einen Halbdeckel D, die Temperatur des Dampfes durch ein in den Dampfmantel einführbares Thermometer controlirt. Um den Apparat mit der Mischung zu beschicken, wird entweder durch die zur Aufnahme des Dampfmantelthermometers dienende Tülle oder nach Lösung der Verschraubung bei $m$ und Entfernung des Kühlbassins durch das Hauptrohr n eingegossen. Das anzuwendende Quantum beträgt nicht unter 100 und nicht über $150 \mathrm{ccm}$. Erhitzt man uun mittelst eines etwa gliedlang brennenden Bunsenbrenners direct die untere Bodenfläche des Siedebassins - das Wasserbad ist, wie schon erwälnt, keineswegs erforderlich — so steigen die Dämpfe in dem durch Asbestpappe isolirten Hollmantel Ahk sowohl wie in dem mittleren Hauptrohr n auf, verbreiten sich durch die Dampfcommunicationsröhren l, werden dann in der Schlange $\mathrm{E}$ condensirt und fliessen hierauf tropfbar flüssig nach dem Siedebassin zurück, um von hier ihre Wanderung von Neuem zu beginnen. Durch die Communication der Röhren $\mathrm{n}$ und $\mathrm{l}$ einerseits und die Verbindung derselben mit dem Dampfmantel andererseits ist eine absolut gleichmässige Wärmedurchstrahlung des Sterilisationsraumes garantirt. Die Differenz in. der Temperatur des Dampfes und des Sterilisationsmaterials beträgt nach circa 1 Stunde $0,5^{\circ} \mathrm{C}$. Um den Apparat zu heizen, bedient man sich einer möglichst kleinen Gas- oder Spirituslampe zum Zwecke die Ansammlung grösserer druckerzeugender Flüssigkeitsmengen in der Kühlschlange zu vermeiden. Man iiberzeugt sich leicht von dem richtigen Maass der zugeführten Wärme durch Befühlen des über der Schraubenmuffe $m$ befindlichen Theiles des Hauptrohres, welches an dieser Stelle einen etwas lebhafteren Eindruck wie die Körperwärme hervorrufen muss. Auf die Höhe der Temperatur kann selbstredend eine grössere Flamme nicht influiren, da der Siedepunkt der Yischung ein für allemal derselbe bleibt. Es soll vielmehr nur ein mässiger Siedeprocess durch eine diesem angepasste Flamme hervorgerufen werden, da durch stürnisches Kochen ein Herausschleudern condensirter Flüssigkeit aus der Schlange zu gewärtigen ist. Ein anderes besseres Kriterium für die Lebhaftigkeit des Kochens kann man sich leicht dalurch schaffen, dass man am Ende der Condensationsschlange bei f ein kieines U-förmiges an jedem Theil der Biegung mit einer Kugel versehenes Glasrohr mittelst Kautschuk- oder Korkstopfen s luftdicht einsetzt und dasselbe mit soviel Wasser versieht, dass die Basis der Kugehn eben von demselben berührt wird. Nachdem das Wasser nach Austreibung der im Apparat befindlichen Luft sich bei einer bestimmten Höhe eingestellt hat, wird jeder durch übermässige Condensation im Kühlrohr hervorgerufene Ueberdruck durch Steigen der im offenen Schenkel befindlichen Flüssigkeit angezeigt. Mehr wie $1 \mathrm{Cbcm}$ Wasser in das Röhrchen zu bringen ist nicht rathsam, da grössere Mengen durch Vermehrung des Druckes Erhöhung des Siedepunktes hervorrufen könnten.

Ueber einen von mir nach demselben Princip construirten Coagulationsapparat für Blutserum werde ich in der nächsten Nummer dieses Blattes berichten.
Ich bemerke schliessiich noch, dass der bewährte Techniker auf diesem Gebiet, mein Freund, Herr Dr. Rob. Müncke, Berlin N. W., Louisenstr. 58, Sterilisationsapparate beschriebener Art liefert. Die dazu erforderlichen Mischungen halte ich vorräthig und können von mir bezogen werden. 